\title{
Effect of Fluorine Implantation Dose on Boron Transient Enhanced Diffusion and Boron Thermal Diffusion in $\mathrm{Si}_{1-x} \mathrm{Ge}_{x}$
}

\author{
H. A. W. El Mubarek, M. Karunaratne, J. M. Bonar, G. D. Dilliway, Y. Wang, P. L. F. Hemment, A. F. Willoughby, \\ and P. Ashburn, Member, IEEE
}

\begin{abstract}
This paper studies how boron transient enhanced diffusion (TED) and boron thermal diffusion in $\mathbf{S i}_{1-x} \mathbf{G e}_{x}$ are influenced by a high-energy fluorine implant at a dose in the range $5 \times 10^{14} \mathrm{~cm}^{-2}$ to $1 \times 10^{16} \mathrm{~cm}^{-2}$. Secondary ion mass spectroscopy (SIMS) profiles of boron marker layers are presented for different fluorine doses and compared with fluorine SIMS profiles and transmission electron microscopy (TEM) micrographs to establish the conditions under which boron diffusion is suppressed. The SIMS profiles show that boron thermal diffusion is reduced above a critical $\mathrm{F}^{+}$dose of $7-9 \times 10^{14} \mathrm{~cm}^{-2}$, whereas boron TED is suppressed at all doses. Fitting of the measured boron profiles gives suppressions of boron TED diffusion coefficients by factors of 6.8, 10.6, and 12.9 and of boron thermal diffusion coefficient by factors of 1.9, 2.5, and 3.5 for $\mathrm{F}^{+}$implantation doses of $9 \times 10^{14}, 1.4 \times 10^{15}$, and $2.3 \times 10^{15} \mathrm{~cm}^{-2}$ respectively. The reduction of boron thermal diffusion above the critical fluorine dose correlates with the appearance of a shallow fluorine peak on the SIMS profile in the vicinity of the boron marker layer, which is attributed to vacancy-fluorine clusters. This reduction of boron thermal diffusion is explained by the effect of the clusters in suppressing the interstitial concentration in the $\mathrm{Si}_{1-x} \mathrm{Ge}_{x}$ layer. The suppression of boron TED correlates with a deep fluorine peak around the range of the fluorine implant and TEM micrographs show that this peak is due to a band of dislocation loops. This suppression of boron TED is explained by the retention of interstitials in the dislocation loops, which suppresses their backflow to the surface. The fluorine SIMS profiles show that the fluorine concentration in the $\mathbf{S i}_{1-x} \mathbf{G e}_{x}$ layer increases with increasing germanium concentration and that the fluorine concentration in the $\mathrm{Si}_{1-x} \mathbf{G e}_{x}$ layer after anneal is much higher than after implant. This indicates that fluorine is transported into the $\mathrm{Si}_{1-x} \mathrm{Ge}_{x}$ layer from the adjacent silicon, and is explained by the lower formation energy for vacancies in $\mathrm{Ge}$ than in $\mathrm{Si}$. This accumulation of fluorine in the $\mathrm{Si}_{1-x} \mathrm{Ge}_{x}$ layer during anneal is advantageous for devices like SiGe heterojunction bipolar transistors, where the boron must be kept within the $\mathrm{Si}_{1-x} \mathrm{Ge}_{x}$ layer.
\end{abstract}

Index Terms-Boron diffusion, diffusion suppression, fluorine, heterojunction bipolar transistors (HBTs), $\mathrm{Si}_{1-x} \mathrm{Ge}_{x}$, thermal diffusion, transient enhanced diffusion (TED).

Manuscript received October 20, 2004; revised January 19, 2005. This work was supported in part by the Engineering and Physical Sciences Research Council and in part by the European Commission (SINANO project). The review of this paper was arranged by Editor C. McAndrew.

H. A. W. El Mubarek, J. M. Bonar, G. D. Dilliway, and P. Ashburn are with the School of Electronics \& Computer Science, University of Southampton, Southampton SO17 1BJ, U.K. (e-mail: pa@ecs.soton.ac.uk).

M. Karunaratne and A. F. Willoughby are with the Department of Materials, University of Southampton, Southampton, U.K SO17 1BJ.

Y. Wang and P. L. F. Hemment are with the School of Electrical and Electronic Engineering, University of Surrey, Guildford GU2 7XH, U.K.

Digital Object Identifier 10.1109/TED.2005.844738

\section{INTRODUCTION}

$\mathbf{T}$ HE RECENT integration of $\mathrm{Si}_{1-x} \mathrm{Ge}_{x}$ alloys into silicon technologies has made it possible to incorporate bandgap engineering concepts into silicon devices that were previously only possible in compound semiconductor devices. The $\mathrm{Si}_{1-x} \mathrm{Ge}_{x}$ heterojunction bipolar transistor (HBT) [1] was the first example of the exploitation of bandgap engineering in silicon technology and further applications are currently being developed, such as the p-channel $\mathrm{Si}_{1-x} \mathrm{Ge}_{x}$ MOSFET with a compressively strained- $\mathrm{Si}_{1-x} \mathrm{Ge}_{x}$ channel [2] and the n-channel strained-Si MOSFET [3] with a tensile strained-Si channel grown on a $\mathrm{Si}_{1-x} \mathrm{Ge}_{x}$ virtual substrate.

The increasing use of $\mathrm{Si}_{1-x} \mathrm{Ge}_{x}$ in bipolar and MOS transistors highlights the need to better understand dopant diffusion in $\mathrm{Si}_{1-x} \mathrm{Ge}_{x}$ and in particular to investigate methods of reducing dopant diffusion, which has been shown to significantly degrade device performance. In $\mathrm{Si}_{1-x} \mathrm{Ge}_{x}$ HBTs, outdiffusion of boron from the $\mathrm{Si}_{1-x} \mathrm{Ge}_{x}$ base creates potential energy barriers [4] and limits the achievable basewidth, both of which degrade the achievable value of $f_{T}$ and $f_{\max }$ [5]. In $\mathrm{Si}_{1-x} \mathrm{Ge}_{x}$ and strained-Si MOSFETs diffusion of boron in the pocket and the highly doped source/drain has detrimental effects on short-channel effects [6]. Boron diffusion can arise from thermal diffusion during annealing of deposited boron-doped layers and from transient enhanced diffusion (TED) [7] due to the annealing of ion implanted layers.

Over the past few years, considerable research effort has been invested in the search for methods of reducing boron diffusion in $\mathrm{Si}$ and $\mathrm{Si}_{1-x} \mathrm{Ge}_{x}$. The incorporation of carbon into $\mathrm{Si}_{1-x} \mathrm{Ge}_{x}$ during growth has been shown to significantly reduce boron diffusion in $\mathrm{Si}_{1-x} \mathrm{Ge}_{x}$ [8] and has delivered $\mathrm{Si}_{1-x} \mathrm{Ge}_{x}$ HBTs with values of $f_{T}$ and $f_{\max }$ approaching $300 \mathrm{GHz}$ [5]. While this is a simple and effective method of controlling boron diffusion in $\mathrm{Si}_{1-x} \mathrm{Ge}_{x}$ HBTs, it is not without difficulties. For example, interstitial carbon increases substantially at higher carbon contents [9]. Fluorine implantation has also been studied as a method of reducing boron diffusion in silicon, and it has been shown that fluorine both suppresses boron TED in silicon [10]-[16] and boron thermal diffusion [17]. Recently, the authors have also shown that fluorine suppresses boron diffusion in $\mathrm{Si}_{1-x} \mathrm{Ge}_{x}$ [18] [19].

In this paper, a study is made of the effect of fluorine implantation dose on boron TED and boron thermal diffusion in 


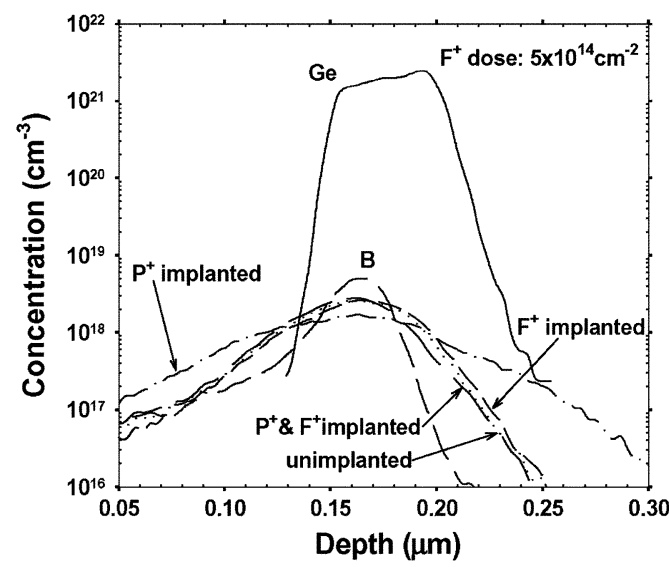

(a)

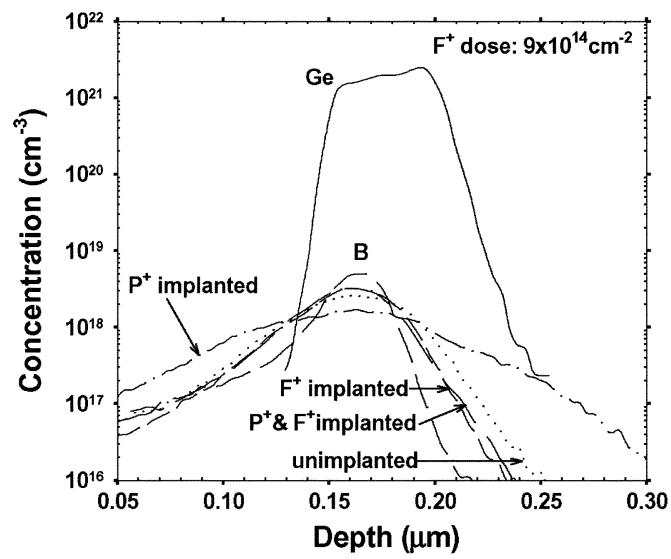

(c)

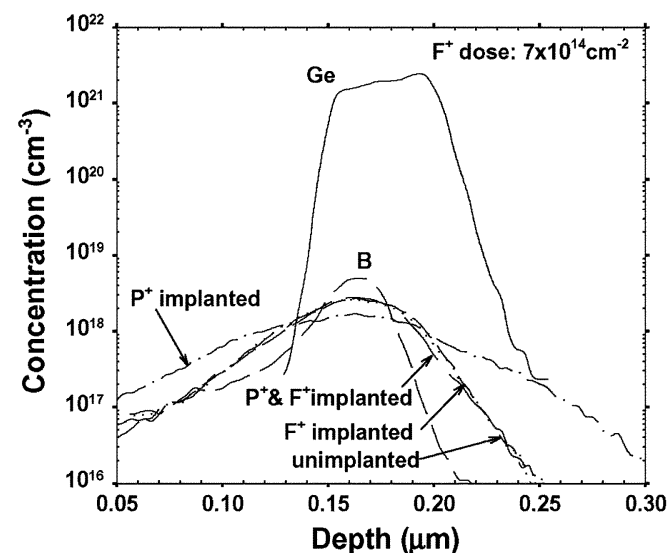

(b)

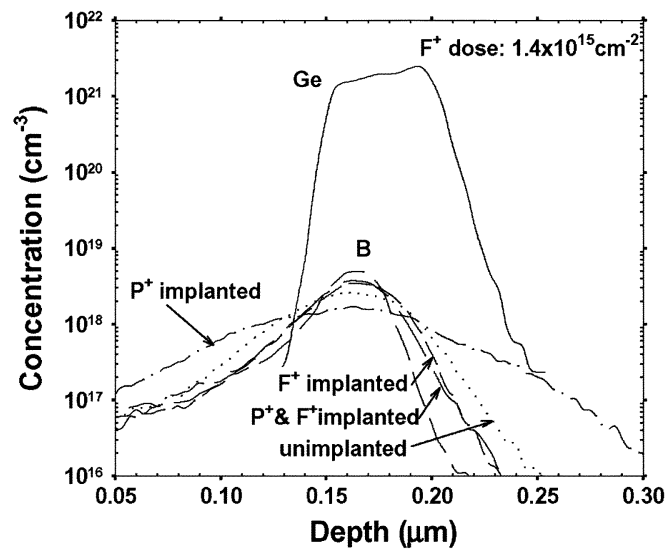

(d)

Fig. 1. Boron profiles after anneal at $1000{ }^{\circ} \mathrm{C}$ for $30 \mathrm{~s}$ in dry nitrogen for growth A samples implanted with $\mathrm{P}^{+}$and $\mathrm{F}^{+}\left(\right.$long dash line), with $\mathrm{P}^{+}$only $($dot dash line), and with $\mathrm{F}^{+}$only (short dash line), and for samples with no implants (dotted line). Results are shown for fluorine implantation doses of (a) $5 \times 10^{14} \mathrm{~cm}^{-2}$, (b) $7 \times 10^{14} \mathrm{~cm}^{-2}$, (c) $9 \times 10^{14} \mathrm{~cm}^{-2}$, and (d) $1.4 \times 10^{15} \mathrm{~cm}^{-2}$. As-grown boron and germanium profiles are also shown for reference.

$\mathrm{Si}_{1-x} \mathrm{Ge}_{x}$. It is shown that boron TED is eliminated at all fluorine doses studied and correlates with a deep fluorine peak at a depth corresponding to the range of the fluorine implant. Reduction of boron thermal diffusion occurs above a critical fluorine dose of $7-9 \times 10^{14} \mathrm{~cm}^{-2}$ and correlates with the appearance of a shallow fluorine peak. Explanations are proposed for the natures of these shallow and deep fluorine peaks and for their effect on boron thermal and TED. Values of boron diffusion coefficient for different fluorine doses are obtained from simulation of the measured profiles.

\section{EXPERIMENTAL PROCEDURE}

Low-pressure chemical vapor deposition at $850{ }^{\circ} \mathrm{C}$ (growth A) and $800{ }^{\circ} \mathrm{C}$ (growth B) was used to grow layers analogous to those used in $\mathrm{Si}_{1-x} \mathrm{Ge}_{x}$ HBTs. Layers grown included a $\mathrm{Si}$ starter layer, a $\mathrm{Si}_{1-x} \mathrm{Ge}_{x}$ layer and a $\mathrm{Si}$ cap layer on a (100) silicon wafer. Boron doped marker layers were incorporated within the $\mathrm{Si}_{1-x} \mathrm{Ge}_{x}$ layers with peak concentrations of $5 \times 10^{18}$ $\mathrm{cm}^{-3}$ (growth A, $6 \% \mathrm{Ge}$ ) and $1.2 \times 10^{19} \mathrm{~cm}^{-3}$ (growth B, $11 \%$ $\mathrm{Ge})$. Four types of samples were then produced from the same wafer; the first had no implants (unimplanted), the second a phosphorus implant only $\left(\mathrm{P}^{+}\right.$implanted), the third a phosphorus and a fluorine implant $\left(\mathrm{P}^{+} \& \mathrm{~F}^{+}\right.$implanted $)$and the fourth a fluorine implant only ( $\mathrm{F}^{+}$implanted). A $288 \mathrm{keV}, 6 \times 10^{13} \mathrm{~cm}^{-2}$ phosphorus implant was used with an energy and dose similar to those used for selective implanted collectors. The $\mathrm{F}^{+}$was implanted at $185 \mathrm{keV}$, with a dose in the range $5 \times 10^{14} \mathrm{~cm}^{-2}$ to $1 \times 10^{16} \mathrm{~cm}^{-2}$ and with the energy chosen to give a fluorine peak coincident with the phosphorus peak. The samples were annealed by rapid thermal annealing in nitrogen at $1000{ }^{\circ} \mathrm{C}$ for $30 \mathrm{~s}$. Boron (B11), fluorine (F19), and germanium (Ge74) concentration depth profiles were obtained on all samples by secondary ion mass spectroscopy (SIMS). The layers were also analyzed by transmission electron microscopy (TEM). The annealed boron SIMS profiles were fitted using the fully coupled diffusion model in the SILVACO ATHENA simulation program and the diffusion coefficients were extracted from the best fits obtained.

\section{RESULTS}

Fig. 1 shows boron SIMS profiles in samples implanted with $\mathrm{F}^{+}$at a dose in the range $5 \times 10^{14} \mathrm{~cm}^{-2}$ to $1.4 \times 10^{15} \mathrm{~cm}^{-2}$ and annealed at $1000^{\circ} \mathrm{C}$. For the sample implanted with $\mathrm{P}^{+}$only ( $\mathrm{P}^{+}$implanted), Fig. 1(a) shows that the anneal gives considerable out-diffusion of the boron profile into the adjacent silicon layers due to TED arising from the point defects introduced by the $\mathrm{P}^{+}$implant. The SIMS profile for the $\mathrm{P}^{+}$and $\mathrm{F}^{+}$implanted sample $\left(\mathrm{P}^{+}\right.$and $\mathrm{F}^{+}$implanted $)$, indicates that the amount of 


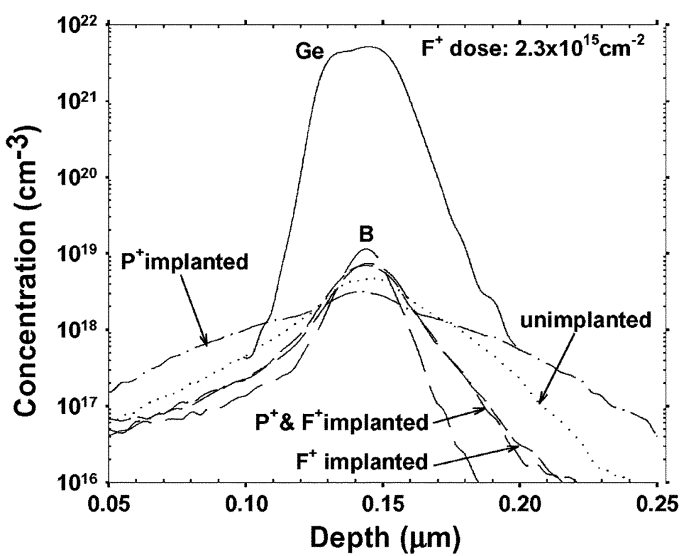

(a)

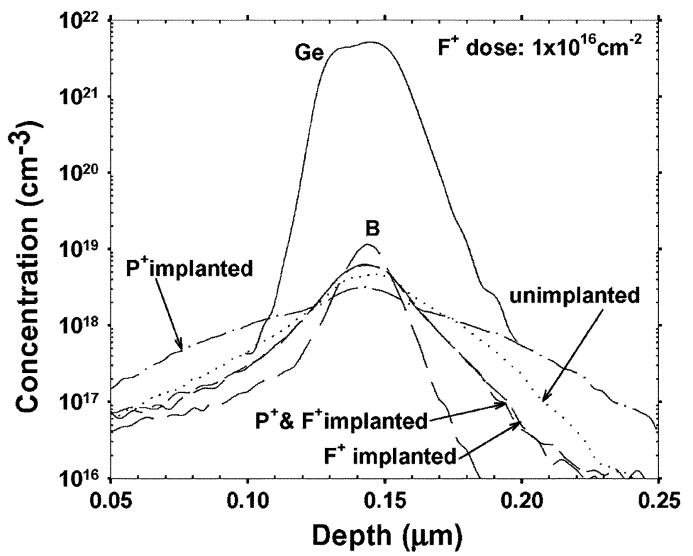

(b)

Fig. 2. Boron profiles after anneal at $1000^{\circ} \mathrm{C}$ for $30 \mathrm{~s}$ for growth $\mathrm{B}$ samples implanted with $\mathrm{P}^{+}$and $\mathrm{F}^{+}$(long dash line), with $\mathrm{P}^{+}$only (dot dash line) and with $\mathrm{F}^{+}$only (short dash line), and for samples with no implants (dotted line). Results are shown for fluorine implantation doses of (a) $2.3 \times 10^{14} \mathrm{~cm}^{-2}$, and (b) $1 \times 10^{16} \mathrm{~cm}^{-2}$. As-grown boron and germanium profiles are also shown for reference.

boron diffusion is dramatically less than that in the sample implanted with $\mathrm{P}^{+}$only and is comparable with the amount of boron diffusion in the unimplanted sample (unimplanted). This indicates that the $5 \times 10^{14} \mathrm{~cm}^{-2} \mathrm{~F}^{+}$implant has completely suppressed boron TED resulting from the phosphorus implant. Similar results are seen in Fig. 1(b) for a $\mathrm{F}^{+}$implant of $7 \times 10^{14}$ $\mathrm{cm}^{-2}$.

Fig. 1(c) shows SIMS profiles for a $9 \times 10^{14} \mathrm{~cm}^{-2} \mathrm{~F}^{+}$implant and very different behavior is observed. In this case, the amount of boron diffusion in the $\mathrm{P}^{+} \& \mathrm{~F}^{+}$implanted sample is not only dramatically less than that in the sample implanted with $\mathrm{P}^{+}$only, but also significantly less than that in the unimplanted sample. Furthermore, the amount of boron diffusion in the $\mathrm{P}^{+} \& \mathrm{~F}^{+}$ implanted sample is similar to that in the $\mathrm{F}^{+}$implanted sample $\left(\mathrm{F}^{+}\right.$implanted). These results indicate that a $9 \times 10^{14} \mathrm{~cm}^{-2} \mathrm{~F}^{+}$ implant not only suppresses boron TED but also significantly decreases boron thermal diffusion. Similar behavior is seen for a $\mathrm{F}^{+}$dose of $1.4 \times 10^{15} \mathrm{~cm}^{-2}$, as shown in Fig. 1(d).

Fig. 2 shows boron SIMS profiles in samples implanted with higher $\mathrm{F}^{+}$doses of $2.3 \times 10^{15} \mathrm{~cm}^{-2}$ (Fig. 2(a)) and $1 \times 10^{16}$ $\mathrm{cm}^{-2}$ [Fig. 2(b)]. It should be noted that these profiles were obtained on a different wafer (growth B) than those in Fig. 1
TABLE I

SUMMARY OF THE REDUCTION OF BORON DIFFUSION COEFFICIENT IN SAMPLES ImPlanted With $\mathrm{P}^{+} \& \mathrm{~F}^{+}$AND With $\mathrm{F}^{+}$OnLY. The VALUES OF BORON DIFFUSION COEFFICIENT FOR THE $\mathrm{P}^{+}$and $\mathrm{F}^{+}$IMPLANTED SAMPLES WERE NORMALISED TO THE DIFFUSION COEFFICIENT FOR THE $\mathrm{P}^{+}$IMPLANTED SAMPLE AND THE VALUES OF BORON DifFusion COEFFICIENT FOR THE $\mathrm{F}^{+}$IMPLANTED SAMPLES WeRE NORMALISED TO THE DifFUSION COEFFICIENT FOR THE UNIMPLANTED SAMPLE

\begin{tabular}{c|c|c}
\hline Implant Type & $\begin{array}{c}\mathbf{F}^{+} \text {Implant Dose } \\
\mathbf{c m}^{-2}\end{array}$ & $\begin{array}{c}\text { Diffusion Reduction } \\
\text { Factor }\end{array}$ \\
\hline $\mathrm{P}^{+}$implanted & - & 1 \\
\hline $\mathrm{P}^{+} \& \mathrm{~F}^{+}$ & $5 \times 10^{14}$ & 4.0 \\
\hline $\mathrm{P}^{+} \& \mathrm{~F}^{+}$ & $7 \times 10^{14}$ & 4.0 \\
\hline $\mathrm{P}^{+} \& \mathrm{~F}^{+}$ & $9 \times 10^{14}$ & 6.8 \\
\hline $\mathrm{P}^{+} \& \mathrm{~F}^{+}$ & $1.4 \times 10^{15}$ & 10.6 \\
\hline $\mathrm{P}^{+} \& \mathrm{~F}^{+}$ & $2.3 \times 10^{15}$ & 12.9 \\
\hline $\mathrm{P}^{+} \& \mathrm{~F}^{+}$ & $1 \times 10^{16}$ & 7.8 \\
\hline unimplanted $_{\mathrm{F}^{+} \text {only }}$ & $5 \times 10^{14}$ & 1 \\
\hline $\mathrm{F}^{+}$only & $7 \times 10^{14}$ & - \\
\hline $\mathrm{F}^{+}$only & $9 \times 10^{14}$ & - \\
\hline $\mathrm{F}^{+}$only & $1.4 \times 10^{15}$ & 1.9 \\
\hline $\mathrm{F}^{+}$only & $2.3 \times 10^{15}$ & 2.5 \\
\hline $\mathrm{F}^{+}$only & $1 \times 10^{16}$ & 3.5 \\
\hline
\end{tabular}

(growth A). These samples show a similar trend to that seen in Fig. 1(d), namely these high dose $\mathrm{F}^{+}$implants not only suppress boron TED resulting from the $\mathrm{P}^{+}$implant but also significantly decrease boron thermal diffusion.

Values of boron diffusion coefficient were extracted by fitting to the measured boron profiles and values of diffusion reduction factor are summarized in Table I. For the sample implanted with $\mathrm{P}^{+}$and $2.3 \times 10^{15} \mathrm{~cm}^{-2} \mathrm{~F}^{+}$, the fluorine implant reduced the boron diffusion coefficient by a factor of 12.9 compared with the $\mathrm{P}^{+}$implanted sample.

Fig. 3 shows fluorine SIMS profiles in growth A samples implanted with $\mathrm{P}^{+} \& \mathrm{~F}^{+}$at a dose in the range $5 \times 10^{14} \mathrm{~cm}^{-2}$ to $1.4 \times 10^{15} \mathrm{~cm}^{-2}$ and annealed at $1000{ }^{\circ} \mathrm{C}$. For the two lowest fluorine implantation doses of $5 \times 10^{14} \mathrm{~cm}^{-2}$ and $7 \times 10^{14}$ $\mathrm{cm}^{-2}$, negligible fluorine is present (at the SIMS background of $\approx 1 \times 10^{17} \mathrm{~cm}^{-3}$ ) in the vicinity of the $\mathrm{Si}_{1-x} \mathrm{Ge}_{x}$ layer after anneal. The majority of the fluorine is located in a broad peak, which for a $\mathrm{F}^{+}$dose of $5 \times 10^{14} \mathrm{~cm}^{-2}$ is slightly deeper than the range of the fluorine implant $(\approx 0.41 \mu \mathrm{m})$, and for a $\mathrm{F}^{+}$dose of $7 \times 10^{14} \mathrm{~cm}^{-2}$ is at a similar depth as the fluorine implant $(\approx 0.41 \mu \mathrm{m})$. For a fluorine dose of $9 \times 10^{14} \mathrm{~cm}^{-2}$, Fig. 3(c) shows two additional peaks in the $\mathrm{Si}_{1-x} \mathrm{Ge}_{x}$ layer at depths of 0.16 and $0.19 \mu \mathrm{m}$, which correspond with the positions of the top and bottom heterojunction interfaces. A small shoulder on the deep fluorine peak can also be seen between 0.22 and 0.28 $\mu \mathrm{m}$. For a F ${ }^{+}$dose of $1.4 \times 10^{15} \mathrm{~cm}^{-2}$, Fig. 3(d) shows a similar set of fluorine peaks as seen in Fig. 3(c). An interesting feature of the peak at the bottom heterojunction interface $(0.19 \mu \mathrm{m}$ peak) is that the fluorine concentration after anneal $\left(3 \times 10^{19}\right.$ $\mathrm{cm}^{-3}$ ) is considerably higher than the concentration at the same depth after implant $\left(1 \times 10^{19} \mathrm{~cm}^{-3}\right)$.

Fig. 4 shows fluorine SIMS profiles of samples implanted with $\mathrm{P}^{+}$and $\mathrm{F}^{+}$at a dose of $2.3 \times 10^{15} \mathrm{~cm}^{-2}$ or $1 \times 10^{16}$ $\mathrm{cm}^{-2}$ and annealed at $1000^{\circ} \mathrm{C}$. It should be noted that these profiles were obtained on a different wafer (growth B) than those in Fig. 3 (growth A). For a $\mathrm{F}^{+}$dose of $2.3 \times 10^{15} \mathrm{~cm}^{-2}$, Fig. 4(a) shows two peaks in the $\mathrm{Si}_{1-x} \mathrm{Ge}_{x}$ layer at the top and bottom 


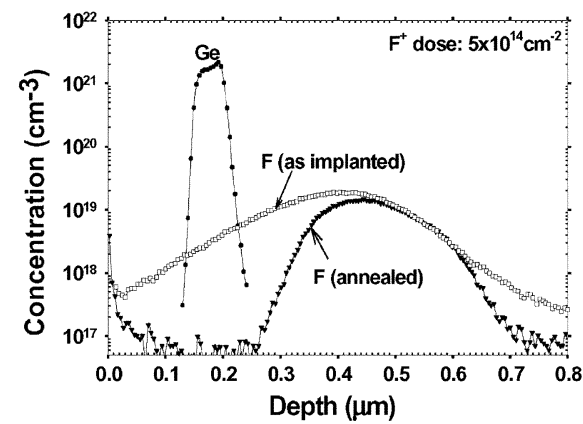

(a)

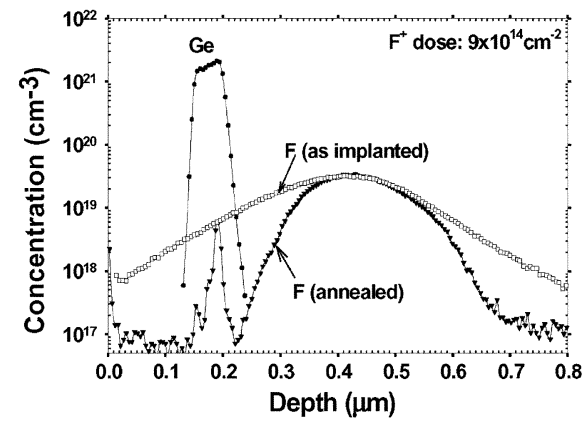

(c)

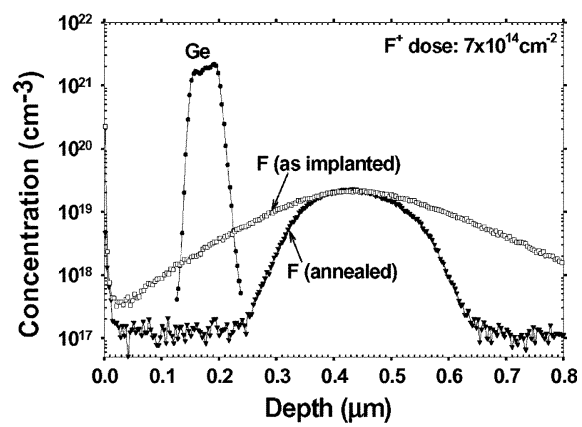

(b)

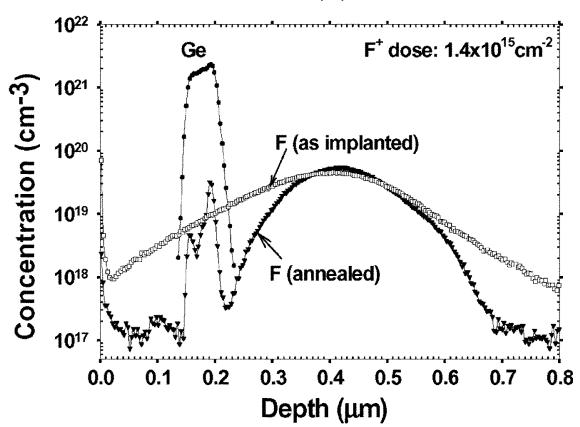

(d)

Fig. 3. Fluorine SIMS profiles before and after anneal for growth A samples implanted with (a) $5 \times 10^{14} \mathrm{~cm}^{-2}$, (b) $7 \times 10^{14} \mathrm{~cm}^{-2}$, (c) $9 \times 10^{14} \mathrm{~cm}^{-2}$, and (d) $1.4 \times 10^{15} \mathrm{~cm}^{-2}$. The corresponding germanium profiles after anneal are shown for reference.

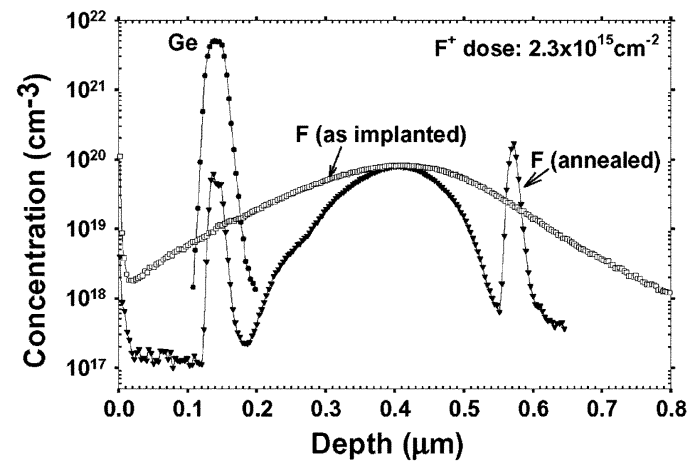

(a)

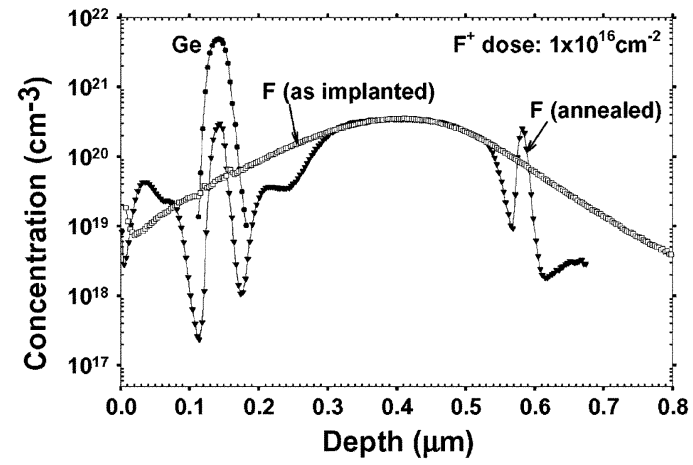

(b)

Fig. 4. Fluorine SIMS profiles before and after anneal for growth B samples implanted with $\mathrm{P}^{+}$and $\mathrm{F}^{+}$at fluorine implantation doses of (a) $2.3 \times 10^{15}$ $\mathrm{cm}^{-2}$, and (b) $1 \times 10^{16} \mathrm{~cm}^{-2}$. The corresponding germanium profiles after anneal are shown for reference.

heterojunction interfaces. The fluorine concentrations at both interfaces after anneal are considerably higher than the equivalent concentrations at the same depth after implant. This indicates
TABLE II

SUMMARY OF FLUORINE CONCENTRATIONS AT THE TOP AND BOTTOM $\mathrm{Si}_{1-x} \mathrm{Ge}_{x} / \mathrm{Si}$ HETEROJUNCTION INTERFACES AFTER IMPLANT AND AFTER ANNEAL AT $1000{ }^{\circ} \mathrm{C}$ FOR FLUORINE IMPLANTS AT DOSES IN THE RANGE $5 \times 10^{14} \mathrm{~cm}^{-2}$ TO $1 \times 10^{16} \mathrm{~cm}^{-2}$

\begin{tabular}{c|c|c|c|c}
\hline \multirow{2}{*}{$\begin{array}{c}\text { Fluorine } \\
\text { implant } \\
\text { dose } \\
\mathbf{c m}^{-2}\end{array}$} & \multicolumn{3}{|c}{ Peak fluorine concentration in the SiGe layer, cm } \\
\cline { 2 - 5 } & \multicolumn{2}{|c}{ After implant } & \multicolumn{2}{c}{ After anneal } \\
\cline { 2 - 5 } & Bottom interface & Top interface & Bottom interface & Top interface \\
\hline $5 \times 10^{14}$ & $3.1 \times 10^{18}$ & $1.9 \times 10^{18}$ & $<10^{17}$ & $<10^{17}$ \\
\hline $7 \times 10^{14}$ & $3.7 \times 10^{18}$ & $2.1 \times 10^{18}$ & $\approx 10^{17}$ & $\approx 10^{17}$ \\
\hline $9 \times 10^{14}$ & $6.0 \times 10^{18}$ & $3.9 \times 10^{18}$ & $5 \times 10^{18}$ & $3 \times 10^{17}$ \\
\hline $1.4 \times 10^{15}$ & $1 \times 10^{19}$ & $7 \times 10^{18}$ & $3 \times 10^{19}$ & $5 \times 10^{18}$ \\
\hline $2.3 \times 10^{15}$ & $1.3 \times 10^{19}$ & $1 \times 10^{19}$ & $4 \times 10^{19}$ & $6 \times 10^{19}$ \\
\hline $1 \times 10^{16}$ & $5 \times 10^{19}$ & - & $3 \times 10^{20}$ & - \\
\hline
\end{tabular}

that fluorine is being transported into the $\mathrm{Si}_{1-x} \mathrm{Ge}_{x}$ layer from the adjacent $\mathrm{Si}$ layers and is then accumulating in the $\mathrm{Si}_{1-x} \mathrm{Ge}_{x}$. A shoulder is again present between 0.22 and $0.28 \mu \mathrm{m}$, and a deep peak at a depth corresponding approximately with the range of the fluorine implant $(\approx 0.41 \mu \mathrm{m})$. A sharp fluorine peak is also present at a depth of $0.57 \mu \mathrm{m}$, which corresponds with the original growth interface. For a $\mathrm{F}^{+}$dose of $1 \times 10^{16} \mathrm{~cm}^{-2}$, Fig. 4(b) shows the presence of an additional shallow fluorine peak in the silicon cap layer at a depth between 0.03 and 0.08 $\mu \mathrm{m}$. Furthermore, the fluorine shoulder between 0.20 and 0.24 $\mu \mathrm{m}$ is more distinct than at lower fluorine doses and the deep fluorine peak is considerably broader.

Table II summarizes the peak fluorine concentrations at the top and bottom heterojunction interfaces after implant and after anneal. The results after anneal show that once the fluorine peaks in the $\mathrm{Si}_{1-x} \mathrm{Ge}_{x}$ layer form at a $\mathrm{F}^{+}$implant 


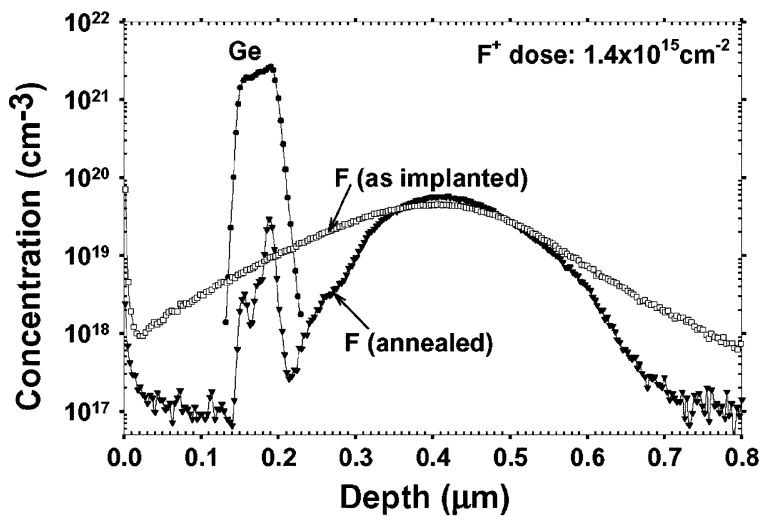

Fig. 5. Fluorine SIMS profiles before and after anneal for growth A samples implanted with $\mathrm{F}^{+}$only at a dose of $1.4 \times 10^{15} \mathrm{~cm}^{-2}$. The corresponding germanium profile after anneal is shown for reference.

dose of $9 \times 10^{14} \mathrm{~cm}^{-2}$, the concentrations at both interfaces rise strongly with increasing fluorine dose. At high $\mathrm{F}^{+}$doses, the fluorine concentrations after anneal become much higher than the equivalent values after implant. It is also interesting to note that for $\mathrm{F}^{+}$doses of $9 \times 10^{14}$ and $1.4 \times 10^{15} \mathrm{~cm}^{-2}$, the fluorine concentration after anneal at the bottom interface is significantly higher than at the top interface. The fluorine and germanium profiles in Fig. 3 show that this higher fluorine concentration correlates with a higher germanium concentration.

Fluorine SIMS profiles were also measured for samples implanted with $\mathrm{F}^{+}$only (no $\mathrm{P}^{+}$implant) at doses in the range $5 \times 10^{14} \mathrm{~cm}^{-2}$ to $1 \times 10^{16} \mathrm{~cm}^{-2}$. An example is shown in Fig. 5 for $\mathrm{a} \mathrm{F}^{+}$implant of $1.4 \times 10^{15} \mathrm{~cm}^{-2}$. It can be seen that this profile is nearly identical to that in Fig. 3(d). The same result was obtained for all the other fluorine doses, indicating that the fluorine profiles are not significantly influenced by the presence of the phosphorus.

Fig. 6(a) and (b) shows cross-sectional TEM micrographs of a sample implanted with $\mathrm{P}^{+}$and $5 \times 10^{14} \mathrm{~cm}^{-2} \mathrm{~F}^{+}$and annealed at $1000{ }^{\circ} \mathrm{C}$ and Figs. 6(c) and (d) show micrographs of a sample from the same wafer, implanted with a $\mathrm{F}^{+}$dose of $2.3 \times 10^{15}$ $\mathrm{cm}^{-2}$. Fig. 6(a) shows a band of defects extending from a depth of about 0.30 to $0.51 \mu \mathrm{m}$ and a line of defects at a depth of 0.57 $\mu \mathrm{m}$, which corresponds with the depth of the growth interface. No defects are seen at depths shallower than $0.30 \mu \mathrm{m}$ and in particular no defects are seen in the $\mathrm{Si}_{1-x} \mathrm{Ge}_{x}$ layer, which can be seen as a dark band in the micrograph. The higher magnification micrograph in Fig. 6(b) shows that the defects consist of dislocation loops of various sizes ranging from around 16 to $62 \mathrm{~nm}$. For the higher $\mathrm{F}^{+}$dose implant in Fig. 6(c), a band of defects can be seen extending from a depth of 0.28 to $0.52 \mu \mathrm{m}$, together with a line of defects at the growth interface at a depth of $0.57 \mu \mathrm{m}$. Once again no defects are seen in the $\mathrm{Si}_{1-x} \mathrm{Ge}_{x}$ layer. The higher magnification image in Fig. 6(d) shows that the defects consist of dislocation loops, with various shapes and sizes ranging from around 16 to $62 \mathrm{~nm}$. TEM micrographs were also taken after the $\mathrm{P}^{+} \& \mathrm{~F}^{+}$implants and before anneal for both $\mathrm{F}^{+}$doses, and it was found that the implants did not create an amorphous layer.

For comparison, Fig. 7 shows a cross section TEM micrograph of a sample implanted with $\mathrm{P}^{+}$only and annealed at

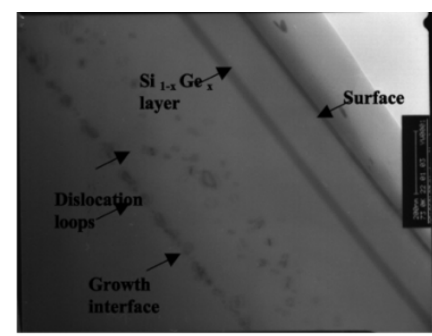

(a)

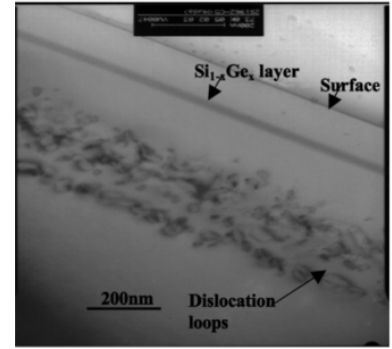

(c)

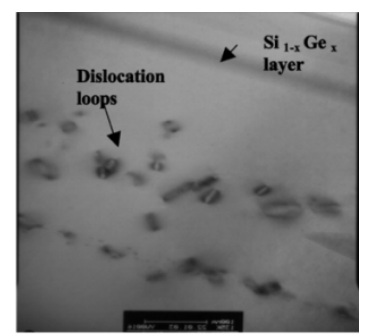

(b)

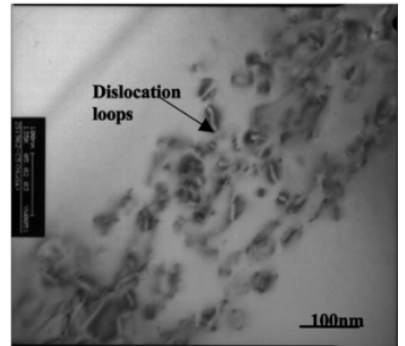

(d)
Fig. 6. Cross-sectional TEM micrographs of samples implanted with $288 \mathrm{keV}$, $6 \times 10^{13} \mathrm{~cm}^{-2} \mathrm{P}^{+}$and $185 \mathrm{keV} \mathrm{F}^{+}$at different doses and annealed for $30 \mathrm{~s}$ in dry nitrogen at $1000{ }^{\circ} \mathrm{C}$; (a) low magnification micrograph for a $5 \times 10^{14}$ $\mathrm{cm}^{-2} \mathrm{~F}^{+}$implant; (b) high magnification micrograph for a $5 \times 10^{14} \mathrm{~cm}^{-2} \mathrm{~F}^{+}$ implant; (c) low magnification micrograph for a $2.3 \times 10^{15} \mathrm{~cm}^{-2} \mathrm{~F}^{+}$implant; (d) high magnification micrograph for a $2.3 \times 10^{15} \mathrm{~cm}^{-2} \mathrm{~F}^{+}$implant.

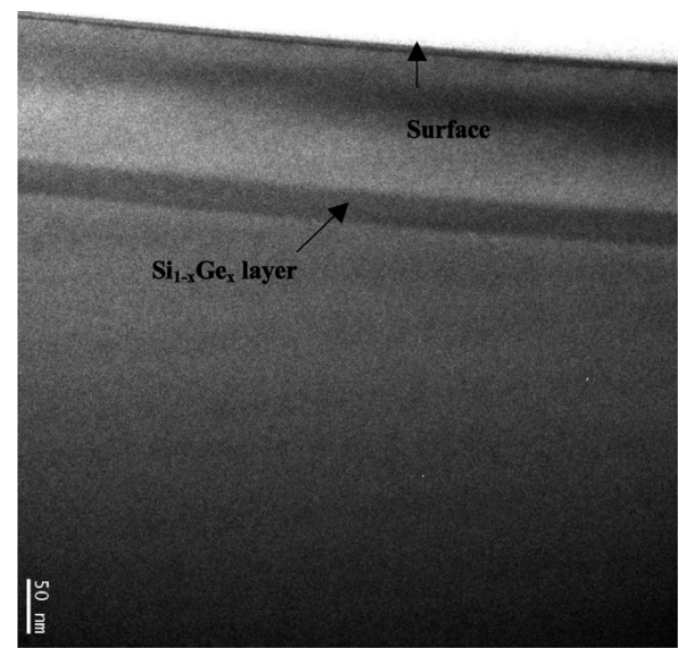

Fig. 7. Cross-sectional TEM micrograph of a sample implanted with $288 \mathrm{keV}$, $6 \times 10^{13} \mathrm{~cm}^{-2} \mathrm{P}^{+}$and annealed for $30 \mathrm{~s}$ in dry nitrogen at $1000{ }^{\circ} \mathrm{C}$.

$1000{ }^{\circ} \mathrm{C}$. In this case, the band of dislocation loops seen in Fig. 6 around the range of the $\mathrm{P}^{+} \& \mathrm{~F}^{+}$implants $(0.41 \mu \mathrm{m})$ is absent. This indicates that the band of dislocation loops is caused by the fluorine implant, rather than the phosphorus implant.

To determine the effect of the boron on the fluorine profile, a $\mathrm{Si}_{1-x} \mathrm{Ge}_{x}$ multilayer structure was grown without any boron and with Ge contents of 10,6 , and 3\%. Fig. 8 shows fluorine SIMS profiles after a $288 \mathrm{keV}, 6 \times 10^{13} \mathrm{~cm}^{-2} \mathrm{P}^{+}$and $185 \mathrm{keV}$, $2.3 \times 10^{15} \mathrm{~cm}^{-2} \mathrm{~F}^{+}$implant and an anneal in dry nitrogen for $30 \mathrm{~s}$ at $1000{ }^{\circ} \mathrm{C}$. The shallowest $\mathrm{Si}_{1-x} \mathrm{Ge}_{x}$ layer lies at a depth of $0.13-0.19 \mu \mathrm{m}$ and shows the presence of a sharp, fluorine 


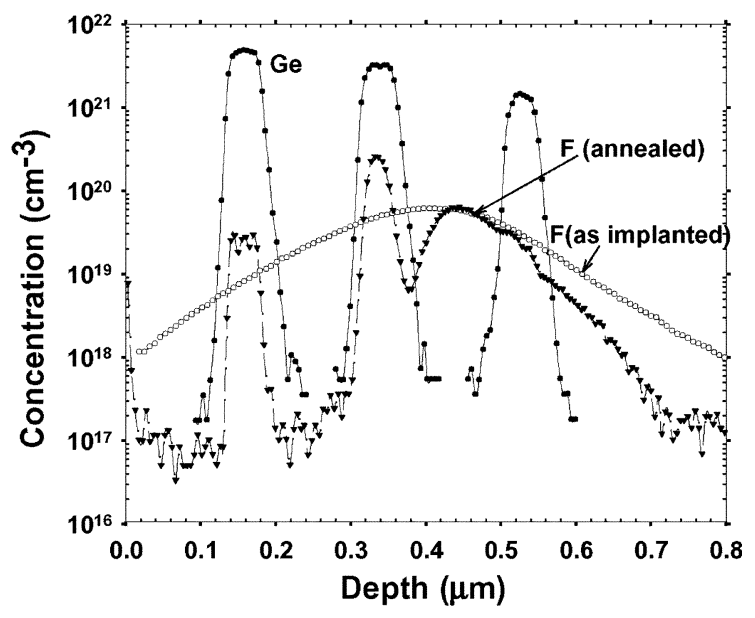

Fig. 8. Fluorine SIMS profile before and after anneal for an undoped $\mathrm{Si}_{1-x} \mathrm{Ge}_{x}$ multilayer structure implanted with $288 \mathrm{keV}, 6 \times 10^{13} \mathrm{~cm}^{-2} \mathrm{P}^{+}$ and $185 \mathrm{keV}, 2.3 \times 10^{15} \mathrm{~cm}^{-2} \mathrm{~F}^{+}$and annealed in dry nitrogen for $30 \mathrm{~s}$ at $1000{ }^{\circ} \mathrm{C}$.

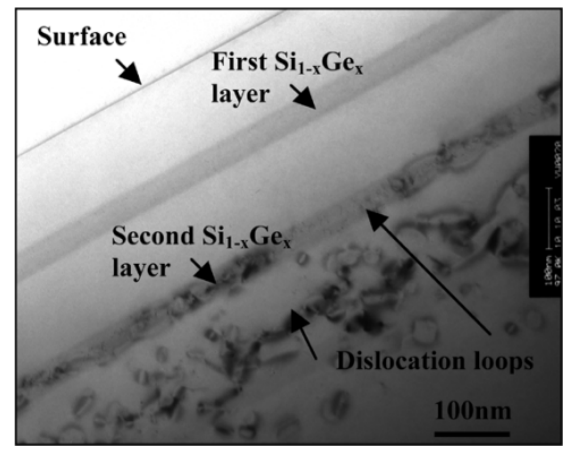

Fig. 9. Cross-sectional TEM micrograph of an undoped $\mathrm{Si}_{1-x} \mathrm{Ge}_{x}$ multilayer structure implanted with $288 \mathrm{keV}, 6 \times 10^{13} \mathrm{~cm}^{-2} \mathrm{P}^{+}$and $185 \mathrm{keV}, 2.3 \times 10^{15}$ $\mathrm{cm}^{-2} \mathrm{~F}^{+}$and annealed in dry nitrogen for $30 \mathrm{~s}$ at $1000{ }^{\circ} \mathrm{C}$.

peak inside the $\mathrm{Si}_{1-x} \mathrm{Ge}_{x}$ layer with a concentration considerably higher after anneal than after implant. The similarity between the shallow fluorine peak in Fig. 4(a) and the shallowest fluorine peak in Fig. 8 indicates that the boron is not responsible for the formation of these fluorine peaks in the $\mathrm{Si}_{1-x} \mathrm{Ge}_{x}$ layers. The middle $\mathrm{Si}_{1-x} \mathrm{Ge}_{x}$ layer lies at a depth of $0.32-0.36 \mu \mathrm{m}$ and again shows the presence of a sharp fluorine peak with a concentration considerably higher after anneal than after implant. The deepest $\mathrm{Si}_{1-x} \mathrm{Ge}_{x}$ layer lies at a depth of $0.5-0.56 \mu \mathrm{m}$ and the fluorine concentration after anneal remains below that after implant throughout the layer.

Fig. 9 shows a cross section TEM micrograph of the $\mathrm{Si}_{1-x} \mathrm{Ge}_{x}$ multilayer structure discussed above. The shallow and middle $\mathrm{Si}_{1-x} \mathrm{Ge}_{x}$ layers can be seen as dark bands, but the deepest $\mathrm{Si}_{1-x} \mathrm{Ge}_{x}$ layer cannot be clearly discerned, presumably because the germanium content is too low (3\%). There are no defects in the vicinity of the shallow $\mathrm{Si}_{1-x} \mathrm{Ge}_{x}$ layer, but a broad band of dislocation loops traverses the deepest $\mathrm{Si}_{1-x} \mathrm{Ge}_{x}$ layer, analogous to those seen earlier in Fig. 6(c) and (d). The middle $\mathrm{Si}_{1-x} \mathrm{Ge}_{x}$ layer shows interesting defect structure, as a line of defects can be seen inside the $\mathrm{Si}_{1-x} \mathrm{Ge}_{x}$ layer, with no defects in the $\mathrm{Si}$ above the $\mathrm{Si}_{1-x} \mathrm{Ge}_{x}$ layer and few defects in the $\mathrm{Si}$ immediately below the $\mathrm{Si}_{1-x} \mathrm{Ge}_{x}$ layer. The defects in the middle $\mathrm{Si}_{1-x} \mathrm{Ge}_{x}$ layer consist of dislocation loops with diameters varying from $16 \mathrm{~nm}$ to $49 \mathrm{~nm}$.

\section{DISCUSSION}

The results in Figs. 1 and 3 show a correlation between a reduction in boron thermal diffusion and the appearance, at a $\mathrm{F}^{+}$dose of $9 \times 10^{14} \mathrm{~cm}^{-2}$, of fluorine peaks in the $\mathrm{Si}_{1-x} \mathrm{Ge}_{x}$ layer. In contrast boron TED is suppressed for all fluorine doses studied and a deep fluorine peak is seen at all doses. These results suggest that the shallow fluorine peak is responsible for the reduction of boron thermal diffusion and the deep fluorine peak for the suppression of boron TED.

The fluorine peaks in the $\mathrm{Si}_{1-x} \mathrm{Ge}_{x}$ layer in Fig. 3 lie at depths of 0.16 and $0.19 \mu \mathrm{m}$, which correspond to 0.35 and $0.48 R_{p}$, where $R_{p}$ is the range of the fluorine implant. These fluorine peaks are not due to the presence of boron as similar fluorine peaks were seen in the undoped $\mathrm{Si}_{1-x} \mathrm{Ge}_{x}$ multilayer structure in Fig. 8. Simulations of vacancy and interstitial profiles after implantation [20], [21] have predicted a vacancy-rich region extending from the surface to a depth approaching the implantation range, $R_{p}$, and a deeper interstitial-rich region peaking at a depth just beyond $\mathrm{R}_{\mathrm{p}}$. This indicates that the fluorine peaks in the $\mathrm{Si}_{1-x} \mathrm{Ge}_{x}$ layer lie in the vacancy-rich region of the damage profile. The TEM micrograph in Fig. 6(c) shows no evidence of line defects in the $\mathrm{Si}_{1-x} \mathrm{Ge}_{x}$ layer and hence any trapping of fluorine at defects in the $\mathrm{Si}_{1-x} \mathrm{Ge}_{x}$ layer must be due to defects that are too small to resolve by TEM. There is considerable evidence in the literature for the formation of vacancy-fluorine clusters in silicon [16], [22], [23], and in our previous work on the effect of fluorine on boron thermal diffusion in silicon [24], we showed that vacancy-fluorine clusters were responsible for a reduction in boron thermal diffusion above a critical fluorine dose of $9 \times 10^{14}$ to $1.4 \times 10^{15} \mathrm{~cm}^{-2}$. In the current work, similar behavior is seen, although the critical fluorine dose in $\mathrm{Si}_{1-x} \mathrm{Ge}_{x}$ is a little lower than that in $\mathrm{Si}$, lying between $7 \times 10^{14}$ and $9 \times 10^{14} \mathrm{~cm}^{-2}$. Given the similarity of our $\mathrm{Si}_{1-x} \mathrm{Ge}_{x}$ results with results in $\mathrm{Si}$, we conclude that the fluorine peaks in the $\mathrm{Si}_{1-x} \mathrm{Ge}_{x}$ layer are due to fluorine trapped at vacancy-fluorine clusters. These clusters would be expected to give rise to a suppression of the interstitial concentration in the $\mathrm{Si}_{1-x} \mathrm{Ge}_{x}$ layer, since any interstitials in the $\mathrm{Si}_{1-x} \mathrm{Ge}_{x}$ could be annihilated at the clusters. Since boron diffusion in $\mathrm{Si}_{1-x} \mathrm{Ge}_{x}$ is mediated by interstitials, an under-saturation of the interstitial concentration in the $\mathrm{Si}_{1-x} \mathrm{Ge}_{x}$ layer would explain the suppression of boron thermal diffusion seen for fluorine doses of $9 \times 10^{14} \mathrm{~cm}^{-2}$ and above.

The deep fluorine peak around the range of the fluorine implant is largely in the interstitial-rich region of the fluorine damage profile, and hence it is likely that it is related in some way to interstitial-fluorine defects. A comparison of the SIMS profiles in Fig. 4(a) with the TEM micrograph in Fig. 6(c), shows that the deep fluorine peak lies between about 0.28 and $0.55 \mu \mathrm{m}$, which compares with the band of dislocation loops between about 0.28 and $0.52 \mu \mathrm{m}$. Thus there is a good correlation with the depth of the dislocation loops, indicating that the deep fluorine peak is due to fluorine trapping at the dislocation loops. A $2.3 \times 10^{15} \mathrm{~cm}^{-2} \mathrm{~F}^{+}$implant does not 
amorphise the silicon layer, and hence these loops are most probably sub-amorphising implantation defects resulting from a super saturation of interstitials in this region [25]. Similar interstitial-type defects have been reported after anneal by $\mathrm{Pi}$ et al. [23] for a $\mathrm{F}^{+}$implant and by Wu et al. [26] for a $\mathrm{BF}_{2}^{+}$ implant.

The generally accepted model for TED of boron is that selfinterstitials are lost from extended $\{311\}$ defects by emission of single interstitial atoms [27]. The released interstitials either diffuse to other defects, such as dislocation loops (Ostwald ripening), or to the surface (dissolution). The diffusion of interstitials to the surface gives rise to TED in boron layers located near the surface. The results in Figs. 6 and 7 show that the band of dislocation loops is present in the samples implanted with $\mathrm{P}^{+} \& \mathrm{~F}^{+}$(Fig. 6) but not in samples implanted with $\mathrm{P}^{+}$only (Fig. 7), indicating that fluorine plays a key role in the formation of the band of dislocation loops. This result suggests that fluorine enhances the Ostwald ripening process, so that self-interstitials lost from $\{311\}$ defects diffuse to the dislocation loops, rather than to the surface. This mechanism would reduce the backflow of interstitials to the surface and hence would explain the suppression of boron TED seen in samples implanted with $\mathrm{P}^{+} \& \mathrm{~F}^{+}$.

The evolution of the shapes of the fluorine peaks in the $\mathrm{Si}_{1-x} \mathrm{Ge}_{x}$ layer in Figs. 3 and 4 with increasing fluorine dose shows some interesting trends. For fluorine doses of $9 \times 10^{14}$ and $1.4 \times 10^{15} \mathrm{~cm}^{-2}$ the fluorine concentration after anneal is much higher at the bottom heterojunction interface than the top interface, as shown in Table II. Fig. 3 shows that the fluorine concentration at the interfaces correlates with the germanium concentrations, which are $2.1 \times 10^{21} \mathrm{~cm}^{-3}$ at the bottom interface and $1.6 \times 10^{21} \mathrm{~cm}^{-3}$ at the top interface. For a fluorine dose of $2.3 \times 10^{15} \mathrm{~cm}^{-2}$ (growth B), the fluorine concentrations after anneal at the two interfaces are similar, which correlates with very similar germanium concentrations at the two interfaces. This correlation between fluorine and germanium concentrations suggests that the concentration of vacancy-fluorine clusters in the $\mathrm{Si}_{1-x} \mathrm{Ge}_{x}$ layer increases with germanium content. The fluorine profiles in Figs. 3(d) and 4 show that the fluorine concentration in the $\mathrm{Si}_{1-x} \mathrm{Ge}_{x}$ layer after anneal is much higher than the concentration after implant and also that the fluorine concentration in the silicon immediately adjacent to the $\mathrm{Si}_{1-x} \mathrm{Ge}_{x}$ layer is much lower than within the $\mathrm{Si}_{1-x} \mathrm{Ge}_{x}$ layer. These results imply the transport of fluorine during the anneal from the adjacent $\mathrm{Si}$ into the $\mathrm{Si}_{1-x} \mathrm{Ge}_{x}$ layer, where it accumulates to reach levels much higher than was present after implant. This result, and the above dependence of fluorine concentration on germanium content, suggests that vacancy-fluorine clusters form more readily in $\mathrm{Si}_{1-x} \mathrm{Ge}_{x}$ than in $\mathrm{Si}$, which could be explained by the lower formation energy of vacancies in $\mathrm{Ge}$ than in $\mathrm{Si}$, as reported by Dalpian et al. [28]. The presence of strain in the $\mathrm{Si}_{1-x} \mathrm{Ge}_{x}$ layer may also have an influence on the vacancy-fluorine cluster formation. Finally, Fig. 3 also shows that the fluorine concentration at the $\mathrm{Si} / \mathrm{Si}_{1-x} \mathrm{Ge}_{x}$ interfaces is lower than the concentration within the $\mathrm{Si}_{1-x} \mathrm{Ge}_{x}$ layer. This result can be explained by the tendency of fluorine to segregate to interfaces [24], as can be seen in Fig. 4, where fluorine is segregated at the growth interface.
For devices like $\mathrm{Si}_{1-x} \mathrm{Ge}_{x}$ HBTs, where the boron needs to be confined within the $\mathrm{Si}_{1-x} \mathrm{Ge}_{x}$ layer, the above migration of fluorine from the adjacent silicon into the $\mathrm{Si}_{1-x} \mathrm{Ge}_{x}$ has important benefits. This mechanism automatically leads to a high fluorine concentration in the $\mathrm{Si}_{1-x} \mathrm{Ge}_{x}$ layer, which is precisely where the boron profile is located in a $\mathrm{Si}_{1-x} \mathrm{Ge}_{x}$ HBT. The effect of the fluorine in reducing the boron thermal diffusion is therefore automatically maximized. Furthermore, this transport of fluorine into the $\mathrm{Si}_{1-x} \mathrm{Ge}_{x}$ layer implies that high concentrations of fluorine can be obtained in the $\mathrm{Si}_{1-x} \mathrm{Ge}_{x}$ layer without the need to precisely position the fluorine implant with respect to the $\mathrm{Si}_{1-x} \mathrm{Ge}_{x}$ layer.

The fluorine SIMS profile for the sample implanted with $1 \times$ $10^{16} \mathrm{~cm}^{-2} \mathrm{~F}^{+}$in Fig. 4(b) shows the presence of an additional surface fluorine peak in the silicon cap layer at a depth between 0.03 and $0.07 \mu \mathrm{m}$. This surface fluorine peak is in the vacancy-rich region of the fluorine damage profile and hence is likely to be due to vacancy-fluorine clusters. Earlier work on the effects of fluorine in silicon [24] showed that a critical fluorine concentration after implant of $3.6-6.6 \times 10^{18} \mathrm{~cm}^{-3}$ was needed for vacancy-fluorine clusters to form in silicon. Fig. 4(b) shows that the fluorine concentration after implant in the vicinity of this additional shallow fluorine peak is between $9 \times 10^{18}$ and $2.4 \times 10^{19} \mathrm{~cm}^{-3} \mathrm{~cm}^{-3}$, which is well above the critical concentration for vacancy-fluorine cluster formation. The presence of this additional shallow fluorine peak in Fig. 4(b) can therefore be explained by the high fluorine concentration in the silicon cap layer after a $1 \times 10^{16} \mathrm{~cm}^{-2} \mathrm{~F}^{+}$implant.

The cross-sectional TEM micrograph of the $\mathrm{Si}_{1-x} \mathrm{Ge}_{x}$ multilayer in Fig. 9 shows no defects in the shallow $\mathrm{Si}_{1-x} \mathrm{Ge}_{x}$ layer but a line of dislocation loops in the middle $\mathrm{Si}_{1-x} \mathrm{Ge}_{x}$ layer. The shallow $\mathrm{Si}_{1-x} \mathrm{Ge}_{x}$ layer lies at a depth of $0.13-0.19 \mu \mathrm{m}$ $\left(0.32-0.46 \mathrm{R}_{\mathrm{p}}\right)$, which places it in the vacancy-rich region of the implant damage profile. In contrast, the middle $\mathrm{Si}_{1-x} \mathrm{Ge}_{x}$ layer lies at a depth of $0.32-0.36 \mu \mathrm{m}\left(0.78-0.88 \mathrm{R}_{\mathrm{p}}\right)$, which places it on the edge of the interstitial-rich region of the damage profile [20], [21]. This suggests that the formation of the dislocation loops in the middle $\mathrm{Si}_{1-x} \mathrm{Ge}_{x}$ layer has been driven by a high interstitial concentration. The absence of loops in the shallow $\mathrm{Si}_{1-x} \mathrm{Ge}_{x}$ layer indicates that a fluorine implant will not generate dislocation loops in $\mathrm{Si}_{1-x} \mathrm{Ge}_{x}$ provided the $\mathrm{Si}_{1-x} \mathrm{Ge}_{x}$ layer is located in the vacancy-rich region of the implant damage profile.

\section{CONCLUSION}

A study has been carried out of the effect of fluorine implants with doses in the range $5 \times 10^{14} \mathrm{~cm}^{-2}$ to $1 \times 10^{16} \mathrm{~cm}^{-2}$ on the TED and thermal diffusion of boron in $\mathrm{Si}_{1-x} \mathrm{Ge}_{x}$. A reduction of boron thermal diffusion is observed for $\mathrm{F}^{+}$doses at and above a dose of $9 \times 10^{14} \mathrm{~cm}^{-2}$, whereas a suppression of boron TED is observed for all $\mathrm{F}^{+}$doses studied. The reduction of boron thermal diffusion correlates with the appearance of fluorine peaks in the $\mathrm{Si}_{1-x} \mathrm{Ge}_{x}$ layer at and above a dose of $9 \times 10^{14}$ $\mathrm{cm}^{-2}$. TEM micrographs show that there are no extended defects in the $\mathrm{Si}_{1-x} \mathrm{Ge}_{x}$ layer, and hence it is proposed that the fluorine peaks are due to vacancy-fluorine clusters. The reduction 
in boron thermal diffusion above the critical $\mathrm{F}^{+}$dose is then explained by the presence of the vacancy-fluorine clusters, which suppress the interstitial concentration in the $\mathrm{Si}_{1-x} \mathrm{Ge}_{x}$ layer. The suppression of boron TED correlates with a deep fluorine peak around the range of the fluorine implant and TEM micrographs show that this peak is due to a band of dislocation loops. The suppression of boron TED by fluorine is then explained by the influence of the loops in suppressing the backflow of interstitials to the surface. Analysis of the SIMS profiles shows that fluorine is transported from the adjacent silicon into the $\mathrm{Si}_{1-x} \mathrm{Ge}_{x}$ layer during anneal, and reaches concentrations that are much higher than observed after implant. This mechanism would give benefits in devices like $\mathrm{Si}_{1-x} \mathrm{Ge}_{x}$ HBTs, where the boron profile needs to be confined within the $\mathrm{Si}_{1-x} \mathrm{Ge}_{x}$ layer, since a high fluorine concentration is automatically obtained in the vicinity of the boron profile, which maximizes the effect of fluorine in suppressing boron diffusion.

\section{REFERENCES}

[1] G. L. Paton, S. S. Iyer, S. L. Delage, S. Tiwari, and J. M. C. Stork, "Silicon-germanium base heterojunction bipolar transistors by molecular beam epitaxy," IEEE Electron Device Lett., vol. 9, no. 3, pp. 165-167, Mar. 1988.

[2] S. Verdonckt-Vanderbroek, E. F. Crabbe, B. S. Meyerson, D. L. Harame, P. J. Restle, J. M. C. Stork, and J. B. Johnson, "SiGe channel heterojunction PMOSFETs," IEEE Trans. Electron Devices, vol. 41, no. 1, pp. 90-101, Jan. 1994

[3] K. Ismail, B. S. Meyerson, S. Rishton, J. Chu, S. Nelson, and L. Nocera, "High-transconductance n-type $\mathrm{Si} / \mathrm{SiGe}$ modulation-doped field-effect transistors," IEEE Electron Device Lett., vol. 13, no. 4, pp. 229-231, Apr. 1992.

[4] Md. R. Hashim, R. F. Lever, and P. Ashburn, "2D simulation of transient enhanced boron out-diffusion from the base of a SiGe HBT due to an extrinsic base implant," Solid State Electron., vol. 43, pp. 131-140, 1999.

[5] B. Jagannathan, M. Khater, F. Pagette, J.-S. Rieh, D. Angell, H. Chen, J. Florkey, F. Golan, D. R. Greenberg, R. Groves, S. J. Jeng, J. Johnson, E. Mengistu, K. T. Schonenberg, C. M. Schnabel, P. Smith, A. Stricker, D. Ahlgren, G. Freeman, K. Stein, and S. Subbanna, "Self aligned SiGe npn transistors with $285 \mathrm{GHz} f_{\max }$ and $207 \mathrm{GHz} f_{T}$ in a manufacturable technology," IEEE Electron Device Lett., vol. 23, no. 4, pp. 258-260, Apr. 2002.

[6] A.-C. Lindgren, P.-E. Hellberg, M. von Haartman, D. Wu, C. Menon, S.-L. Zhang, and M. Östling, "Enhanced intrinsic gain of PMOSFETs with a SiGe channel," in Proc. ESSDERC, 2002, pp. 175-178.

[7] D. J. Eaglesham, P. A. Stolk, H.-J. Gossmann, and J. M. Poate, "Implantation and transient B diffusion in Si: The source of the interstitials," Appl. Phys. Lett., vol. 65, pp. 2305-2307, 1994.

[8] H. Rücker, B. Heinemann, D. Bolze, D. Knoll, D. Krüger, R. Kurps, H. J. Osten, P. Schley, B. Tillack, and P. Zaumseil, "Dopant diffusion in C-doped Si and SiGe: Physical model and experimental verification," in IEDM Tech. Dig., 1999, pp. 345-348.

[9] J. Mi, P. Warren, P. Letourneau, M. Judelewicz, M. Gailhanou, and M. Dutoit, "Effect of RTCVD growth conditions on the crystal quality of pseudomorphic $\mathrm{Si}_{1-x-y} \mathrm{Ge}_{x} \mathrm{C}_{y}$ films," J. Cryst. Growth, vol. 157, pp. 190-194, 1995.

[10] R. G. Wilson, "Boron, fluorine and carrier profiles for $\mathrm{B}$ and $\mathrm{BF}_{2}$ implants into crystalline and amorphous Si," J. Appl. Phys., vol. 54, pp. $6879-6889,1983$.

[11] K. Ohyu, T. Itoga, and N. Natsuaki, "Advantages of fluorine introduction in boron implanted shallow $\mathrm{p}+/ \mathrm{n}$ junction formation," Jpn. J. Appl. Phys., vol. 29, pp. 457-462, 1990

[12] D. Fan, J. M. Parks, and R. J. Jaccodine, "Effect of fluorine on the diffusion of through-oxide implanted boron in silicon," Appl. Phys. Lett., vol. 59, pp. 1212-1214, 1991.
[13] L. Y. Krasnobaev, N. M. Omelyanovskaya, and V. V. Makarov, "The effect of fluorine on the redistribution of boron in ion implanted silicon," J. Appl. Phys., vol. 74, pp. 6020-6022, 1993.

[14] J. Liu, D. F. Downey, K. S. Jones, and E. Ishida, "Fluorine effect on boron diffusion: Chemical or damage?," in Proc. Int. Conf. Ion Implantation Technology, 1999, pp. 951-954.

[15] L. S. Robertson, P. N. Warnes, K. S. Jones, S. K. Earles, M. E. Law, D. F Downey, S. Falk, and J. Liu, "Junction depth reduction of ion implanted boron in silicon through fluorine ion implantation," in Mater. Res. Soc. Symp. Proc., vol. 610, 2000, pp. B4.2.1-B4.2.6.

[16] T. S. Shano, R. Kim, T. Hirose, Y. Furuta, H. Tsuji, M. Furuhashi, and K Taniguchi, "Realization of ultra-shallow junction: Suppressed boron diffusion and activation by optimized fluorine co-implantation," in IEDM Tech. Dig., 2001, pp. 37.4.1-37.4.4.

[17] H. A. W. El Mubarek and P. Ashburn, "Reduction of boron thermal diffusion and elimination of boron transient enhanced diffusion in silicon by high energy fluorine implantation," Appl. Phys. Lett., vol. 83, pp. 4134-4136, 2003.

[18] H. A. W. El Mubarek and P. Ashburn, "Reduction of boron therma diffusion and elimination of boron transient enhanced diffusion in silicon-germanium by high energy fluorine implantation," IEEE Electron Device Lett., vol. 25, no. 8, pp. 535-537, Aug. 2004.

[19] H. A. W. El Mubarek and P. Ashburn, "Semiconductor Processing,", Mar. 2003

[20] M. D. Giles, "Transient phosphorus diffusion below the amorphization threshold," J. Electrochem. Soc., vol. 138, pp. 1160-1165, 1991.

[21] A. Sultan, S. Banerjee, S. List, and V. McNeil, "An approach using a subamorphizing threshold dose silicon implant of optimal energy to achieve shallower junctions," J. Appl. Phys., vol. 83, pp. 8046-8050, 1998.

[22] M. Diebel, S. Chakravarthi, C. F. Machala, S. Ekbote, A. Jain, and S. T. Dunham, "Investigation and modeling of fluorine co-implantation effects on dopant redistribution," in Mater. Res. Soc. Symp. Proc., vol. 765, 2003, pp. D6.15.1-D6.15.6.

[23] X. D. Pi, C. P. Burrows, and P. G. Coleman, "Fluorine in silicon: Diffusion, trapping and precipitation," Phys. Rev. Lett., vol. 90, pp. $155901-$ 1-155901-4, 2003.

[24] H. A. W. El Mubarek, M. Karunaratne, J. M. Bonar, G. D. Dilliway, Y Wang, R. Price, J. Zhang, P. L. F. Hemment, A. F. Willoughby, P. Ward, and P. Ashburn, "Effect of fluorine implantation dose on boron thermal diffusion in silicon," J. Appl. Phys., vol. 96, pp. 4114-4121, 2004.

[25] K. S. Jones, S. Prussin, and E. R. Weber, "A systematic analysis of defects in ion implanted silicon," Appl. Phys. A, vol. 45, pp. 1-34, 1988.

[26] I.-W. Wu, R. T. Fulks, and J. C. Mikkelsen, Jr., "Optimization of BF implanted and rapidly annealed junctions in silicon," J. Appl. Phys., vol. 60, pp. 2422-2438, 1986.

[27] N. E. B. Cowern, M. Jaraiz, F. Cristiano, A. Claverlie, and G. Mannino, "Fundamental diffusion issues for deep-submicron device processing," in IEDM Tech. Dig., 1999, pp. 333-336.

[28] G. M. Dalpian, P. Venezuela, A. J. R. da Silva, and A. Fazzio, "Ab initio calculations of vacancies in $\mathrm{Si}_{x} \mathrm{Ge}_{1-x}$," Appl. Phys. Lett., vol. 81, pp. $3383-3385,2002$

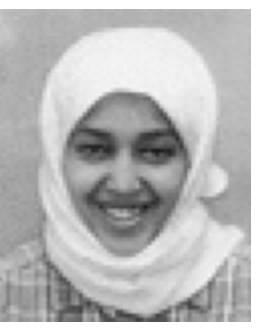

H. A. W. El Mubarek received the B.Eng. and Ph.D degrees in electronic engineering from the University of Southampton, Southampto n, U.K. in 1999 and 2004 , respectively.

Since then she has been working on several research areas including $\mathrm{Si}_{1-x} \mathrm{Ge}_{x}$ and $\mathrm{Si}_{1-x-y} \mathrm{Ge}_{x} \mathrm{C}_{y}$ HBTs on bulk, SOI and SSOI substrates and has over 20 publications. She is currently a Research Assistant at the University of Southampton in an EPSRC-funded collaborative project between the University of Southampton, University of Surrey, Imperial College, Liverpool University, and Queens University, Belfast.

M. Karunaratne, photograph and biography not available at the time of publication 
J. M. Bonar received the B.A. degree in physics from Reed College, Portland, OR, the M.Sc. degree in materials science from Stevens Institute of Technology, Hoboken, NJ and the Ph.D. degree from the Department of Electronics and Computer Science, University of Southampton, U.K. for researc $\mathrm{h}$ in process development in LPCVD growth.

Her research interests include LPCVD growth and structural characterisat ion of $\mathrm{Si}$ and $\mathrm{SiGe}$ for devices and diffusion in $\mathrm{SiGe}$. She has over 60 publications in these and related fields.

G. D. Dilliway, photograph and biography not available at the time of publication.

Y. Wang, photograph and biography not available at the time of publication.

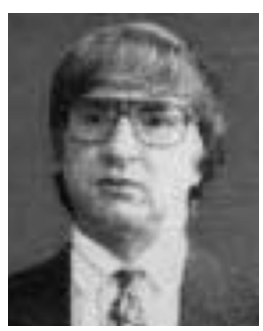

Peter L. F. Hemment (M'84) received the B.Sc., Ph.D., and D.Sc. degrees from the University of Surrey, Guildford, U.K.

He is currently an Emeritus Professorial Research Fellow in the School of Electronics and Physical Sciences, University of Surrey. He has more than 30 years experience in semiconductor processing, specializing in the application of ion beams for the modification and analysis of silicon and related materials. His research initially caused him to address the engineering issues of quality control, then during the 1980s he investigated compound synthesis by high-dose reactive ion implantation and was instrumental in the development of SOI/SIMOX technology. He is internationally recognized for his contribution to the develop ment of SIMOX technology. Subsequently, he investigated applications of SOI materials and the control of extended defects in synthesized Si-SiGe-Si heterostruct ures, suitable for MOS and bipolar device applications, formed by $\mathrm{Ge}+$ implantation into silicon. He has acted as a consultant to the silicon industry, has played an active role in the management of major EU programmes and is committed to furthering international academic collaboration.

Dr. Hemment is a Fellow of FInstP and FIEE, and a chartered member of the Institute of Physics and the Institution of Electrical Engineers.
A. F. Willoughby, photograph and biography not available at the time of publication.

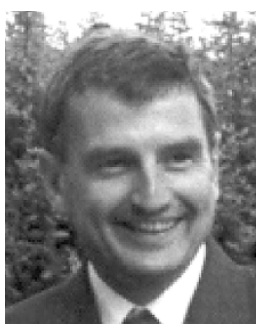

Peter Ashburn (M'98) was born in Rotherham, U.K., in 1950. He received the B.Sc. degree in electrical and electronic engineering and the Ph.D. degree in experimental and theoretical study of radiation damage in silicon $\mathrm{p}-\mathrm{n}$ junctions from the University of Leeds, U.K., in 1971 and 1974, respectively.

In 1974, he joined the Technical Staff of Philips Research Laboratories and worked initially on ion implanted integrated circuit bipolar transistors, and then on electron lithography for submicrometer integrated circuits. In 1978, he joined the Academic Staff of the Department of Electronics and Computer Science, University of Southampton, U.K., as a Lecturer, and currently is the holder of a Personal Chair in microelectronics. Since taking up a post at Southampton University, he has worked on polysilicon emitter bipolar transistors, high-speed bipolar and BiCMOS technologies, gate delay expressions for bipolar circuits, and the effects of fluorine in polysilicon emitters. His current research interests include SiGe HBTs, SiGeC and its device applications and vertical MOS transistors for application in sub-100-nm CMOS technology. He has authored and coauthored 200 papers in the technical literature, given many invited papers on polysilicon emitters, SiGe HBTs and vertical MOSFETs and has authored books on the design and realization of bipolar transistors in 1988 and on silicon germanium HBTs in 2003. 